\title{
Effect of the thyroid status in pregnant patients on the outcome in medical abortion
}

\author{
Nishi Sood ${ }^{1}$, Shyam S. Sud ${ }^{2 *}$ \\ ${ }^{1}$ Department of Obstetrics and Gynecology, Indira Gandhi Medical College, Shimla, Himachal Pradesh, India \\ ${ }^{2}$ Department of Obstetrics and Gynecology, Maharishi Markandeshwar University, Solan, Himachal Pradesh, India
}

Received: 02 August 2018

Accepted: 14 August 2018

\section{*Correspondence:}

Dr. Shyam S. Sud,

E-mail: drshyamsud2000@rediffmail.com

Copyright: $\odot$ the author(s), publisher and licensee Medip Academy. This is an open-access article distributed under the terms of the Creative Commons Attribution Non-Commercial License, which permits unrestricted non-commercial use, distribution, and reproduction in any medium, provided the original work is properly cited.

\section{ABSTRACT}

Background: Medical abortion has the potential to expand abortion services, where surgical services are limited, and to expand women's choice of abortion method and experience. Objective of present study was to compare the outcome after medical abortion in euthyroid and hypothyroid pregnant patients.

Methods: A longitudinal study was carried out in pregnant patients before 9 weeks of pregnancy who wanted termination of pregnancy. Women were divided into two groups. Group I $(n=100)$ comprised euthyroid patients who acted as control group, whereas group II $(n=58)$ included patients having subclinical or overt hypothyroidism. All the patients were given $200 \mathrm{mg}$ of mifepristone orally followed by $800 \mu \mathrm{g}$ of misoprost vaginally 36 to 48 hours later. these patients were followed for 2 weeks. In all the patients, hemoglobin estimation and ultrasound were done during follow-up.

Results: Average hemoglobin in the study group was $9.5 \mathrm{gm} \%$, whereas in control group it was $11.1 \mathrm{gm} \%$, which was statistically significant. the fall in hemoglobin after 2 weeks of the drug intake was also significant in control as well as the study group. About $13.79 \%$ patients in the study group had to undergo emergency evacuation of uterus within 24 hours for complaints of severe bleeding. In control group, no emergency curettage was done within 24 hours, the difference being highly significant. Mean duration of bleeding was also more in the study group. About $28.57 \%$ patients in the study group revealed products of conception on ultrasound after 2 weeks in comparison with $11.57 \%$ in the control group, which was also statistically significant $(\mathrm{p}=0.008)$. A total of $41 \%$ patients in the study group had to undergo uterine curettage, which was highly significant $(\mathrm{p}=0.000)$.

Conclusions: Present study showed that patients having clinical or subclinical hypothyroidism have more failure rates, more chances of excessive bleeding, increased duration of bleeding, resulting in decrease in hemoglobin levels in already anemic patients. Also, the rate of operative intervention was unusually high in hypothyroid group.

Keywords: Failure rate, Hypothyroidism, Medical abortion

\section{INTRODUCTION}

Upto 42 million abortions are performed each year around the globe. ${ }^{1}$ Medical abortion has the potential to expand abortion services, where surgical services are limited, and to expand women's choice of abortion method and experience. Surgical abortion by vacuum aspiration or dilatation and curettage (D and C) has been the method of choice for early pregnancy termination since the 1960s. Medical abortion became an alternative method of first-trimester pregnancy termination with the availability of prostaglandins in the early 1970s followed by the development of an antiprogesterone in the 1980s. large studies suggest that early medical abortion with mifepristone and a prostaglandin is an effective method for pregnancy termination. ${ }^{2}$ Mifepristone in combination with a prostaglandin at up to 63 days of amenorrhea leads to complete abortion in more than $95 \%$ 
of pregnancies. ${ }^{3}$ Some women prefer medical to surgical abortion. "More natural," "being easier," "more private," "and can be done earlier in pregnancy" were reasons to opt for a medical method by some women. ${ }^{4}$ characteristics, such as the method being new, less invasive, and the possibility of verifying the expulsion were reported by others.5

We know that pregnancy with hypothyroidism is associated with a number of adverse outcomes like increased chances of abortion, hypertensive disease of pregnancy, anemia, intrauterine growth restriction, still birth, abruptio placentae, and postpartum hemorrhage. 6 Little is known about pregnancy termination in hypothyroid patients using mifepristone and misoprostol. We carried out a study to see the efficacy of mifepristone and misoprost for medical abortion in hypothyroid patients.

\section{METHODS}

This study was a longitudinal prospective study and carried out in two institutions. Detailed obstetric history of all the patients who asked for medical method of pregnancy termination before 9 weeks was taken. Informed consent was obtained. counseling of the client regarding the nature of medication, side effects, chances of failure was done in detail. General physical examination along with pelvic examination was performed. Hemoglobin, blood grouping, triiodothyronine $(\mathrm{t} 3)$, thyroxine $(\mathrm{t} 4)$, thyroid-stimulating hormone (TSH), urine albumin, urine sugar was measured, and ultrasound was done to confirm intrauterine pregnancy, also dating were done in all patients.

Hundred patients who had normal Thyroid function test acted as control (group I). Fifty- eight patients who had clinical as well as subclinical hypothyroidism were included in this study (group II). For subclinical hypothyroidism cut-off for TSH was $>2.5 \mathrm{mIU} / \mathrm{ml}$ with normal serum levels of $\mathrm{t} 3$ and $\mathrm{t} 4$, whereas overt hypothyroidism was considered when serum $\mathrm{t} 3$ or $\mathrm{t} 4$ were decreased with elevated TSH. the two groups were similar in age, parity, and period of gestation. All the patients were given $200 \mathrm{mg}$ of mifepristone, and 36 to 48 hours later $800 \mu \mathrm{g}$ of misoprost vaginally. Tablet doxycycline $200 \mathrm{mg}$ was also given for 7 days.

The patients were followed up for 2 weeks. Hemoglobin estimation was done at 1 and 2 weeks interval. Ultrasound was done after 2 weeks. the exclusion criteria for the groups were ectopic pregnancy, more than two cesarean sections, parity of more than 4 , history of three or more D\&cs, and hemoglobin $<7 \mathrm{gm} \%$. results were analyzed on following data points:

- need of emergency evacuation of uterus due to profuse bleeding
- (soaking of more than three pads in 1 hour for a 2hour period) and/ or a fall in systolic blood pressure of more than $20 \%$ over the baseline.

- Adverse effects like vomiting, pain, and infection.

- completeness of abortion at 14 days measured by the absence of all the following criteria on Transvaginal ultrasound: endometrial thickness less than $10 \mathrm{~mm}$, solid hyperechoiec mass inside the uterus, presence of fluid levels, presence of choronic villi on histopathological examination after evacuation

- fall in hemoglobin levels at the end of 1 and 2 weeks.

- Satisfaction levels, likelihood of choosing it again, and likelihood of recommending it to a friend.

The results were analyzed for their statistical significance by chi-square test.

\section{RESULTS}

The two groups were comparable in age, parity, and period of gestation as can be seen from Table 1 . The age group of the patients was between 22 and 42 years.

Table 1: Baseline data.

\begin{tabular}{|llll|}
\hline & $\begin{array}{l}\text { Group I } \\
(\mathbf{n}=100)\end{array}$ & $\begin{array}{l}\text { Group II } \\
(\mathbf{n}=58)\end{array}$ & $\begin{array}{l}\mathrm{p} \text { - } \\
\text { value }\end{array}$ \\
\hline Age & $29.5 \pm 5.16$ & $27.28 \pm 4.55$ & 0.552 \\
\hline $\begin{array}{l}\text { Parity } \\
\text { Period of } \\
\text { gestation }\end{array}$ & $6.80 \pm 0.48$ & $1.72 \pm 0.36$ & 0.294 \\
\hline $\begin{array}{l}\text { Previous history } \\
\text { of D\&c }\end{array}$ & 31 & 26 & 0.266 \\
\hline $\begin{array}{l}\text { Previous } \\
\text { history of }\end{array}$ & 17 & 18 & 0.032 \\
\hline LSCS & & & \\
\hline
\end{tabular}

The average period of gestation was $6.804 \pm 1.1093$ in group I and 6.671 \pm 1.2460 in group II. the difference was statistically not significant. Similarly, difference in parity was also not significant $(\mathrm{p}=0.294)$.

Table 2: Status of $\mathrm{Hb}$ in the control versus study group.

\begin{tabular}{|llll|}
\hline $\begin{array}{l}\text { Hemoglobin } \\
\text { value }\end{array}$ & Group I & Group II & p- \\
baseline Hb & $11.180 \pm 1.1447$ & $9.516 \pm 1.0284$ & 0.000 \\
\hline $\begin{array}{l}\text { Hb at } 1^{\text {st }} \\
\text { week }\end{array}$ & $10.6095 \pm 1.15317$ & $9.2328 \pm 0.9859$ & 0.926 \\
\hline $\begin{array}{l}\text { Hb at } 2^{\text {nd }} \\
\text { week }\end{array}$ & $10.1600 \pm 1.09888$ & $8.9832 \pm 1.0557$ & 0.998 \\
\hline \begin{tabular}{l} 
Hb: Hemoglobin \\
\hline
\end{tabular} & & & \\
\hline
\end{tabular}

Both the groups were comparable in parity with parity 2 being the most common in both groups. the difference in history of previous lower segment cesarean section (LSCS) in the study and control groups was statistically significant $(p=0.032)$, whereas the difference in number of previous D\&c procedures in both the groups was not 
statistically significant $(\mathrm{p}=0.266)$. Average hemoglobin in the study group was $9.516 \mathrm{gm} \%$, whereas of control group was $11.180 \mathrm{gm} \%$, which was statistically significant ( $<<0.05$; Table 2).

Table 3: Comparison of $\mathrm{Hb}$ at baseline, $\mathbf{1}^{\text {st }}$ week, and $2^{\text {nd }}$ week in control group $(n=95)$.

\begin{tabular}{|clll|}
\hline Pair 1 & baseline Hb & $1.180 \pm 1.1447$ & \multirow{2}{*}{$<$-value } \\
\cline { 1 - 3 } & Hb at $1^{\text {st }}$ week & $10.6095 \pm 1.15317$ & \\
\cline { 1 - 3 } Pair 2 & baseline Hb & $11.180 \pm 1.1447$ & \multirow{2}{*}{$<0.001$} \\
\hline & Hb at $2^{\text {nd }}$ weeks & $10.1600 \pm 1.09888$ & \\
\hline
\end{tabular}

The mean hemoglobin levels after 7 and 14 days in control group were 10.609 and 10.160 gm\% respectively. This fall in hemoglobin was statistically significant (Table 3).
Table 4: Comparison of $\mathrm{Hb}$ at baseline, $\mathbf{1}^{\text {st }}$ week, and $2^{\text {nd }}$ week in study group $(n=56)$.

\begin{tabular}{|llll|}
\hline \multirow{2}{*}{ Pair 1 } & & Mean & p-value \\
\cline { 3 - 4 } & baseline $\mathrm{Hb}$ & $9.516071+$ & 0.000 \\
& & 1.0284634 & \\
\hline \multirow{2}{*}{ Hb at 1 week } & $9.232857+$ & \\
Pair 2 & baseline Hb & 9.9859111 & \\
& & 1.0284634 & 0.000 \\
\hline & Hb at 2 weeks & $8.983214+$ & \\
& & 1.0557050 & \\
\hline
\end{tabular}

Hb: Hemoglobin

Mean hemoglobin levels in the study group after 1 and 2 week(s) of procedure were 9.232 and $8.983 \mathrm{gm} \%$ respectively. This fall in hemoglobin in the study group after both first and second week was also statistically significant (Table 4).

Table 5: $\mathrm{D}$ and $\mathrm{C}$ in control versus study group.

\begin{tabular}{|c|c|c|c|c|}
\hline Timing of $\mathrm{D}$ and $\mathrm{C}$ & Indications of $\mathbf{D}$ and $\mathbf{C}$ & $\begin{array}{l}\text { Number of } \mathrm{D} \text { and } \mathrm{C} \text { in } \\
\text { group } 1\end{array}$ & $\begin{array}{l}\text { Number of } \mathrm{D} \text { and } \mathrm{C} \text { in } \\
\text { group } 2\end{array}$ & p-value \\
\hline $\begin{array}{l}\text { Emergency D and C } \\
(<24 \text { hours })\end{array}$ & Excessive bleeding & $0(95)$ & $8(48)$ & 0.008 \\
\hline $\mathrm{D}$ and $\mathrm{C}$ at 2 weeks & Retained products of conception & $11(95)$ & $16(56)$ & 0.000 \\
\hline
\end{tabular}

Out of 56 patients in study group, 8 patients $(13.79 \%)$ came within 24 hours with complaints of severe bleeding. emergency evacuation of uterus was done in these patients. two of these patients required blood transfusion.

In control group, no emergency curettage was done within 24 hours and none required blood transfusion within 14 days of observation period. This difference in emergency evacuation for excessive bleeding in both the groups was highly significant $(\mathrm{p}=0.008$; Table 5).

Table 6: Duration of bleeding (in days).

\begin{tabular}{|lll|}
\hline Group & n & Mean \\
\hline I & 95 & $6.77 \pm 2.998$ \\
\hline II & 56 & $8.52 \pm 3.191$ \\
\hline p $<0.001$ & & \\
\hline
\end{tabular}

Mean duration of bleeding was $8.52+3.191$ days in the study group and $6.77+2.998$ days in the control group. the difference in mean duration of bleeding was also highly significant between the two groups $(p=0.001$; Table 6$)$.

Sixteen patients $(28.57 \%)$ in the study group revealed products of conception on ultrasound after 2 weeks. Out of these 16 patients, 1 patient in the study group had viable growing pregnancy despite having bleeding for 6 days. twelve patients $(11.57 \%)$ in the control group had products of conception in uterine cavity after 2 weeks, but none had viable growing pregnancy. this difference in failure of the method between the two groups was statistically significant $(\mathrm{p}=0.000$; Table 5).

Thus, total of 24 patients (including 8 patients undergoing emergency D\&c) in the study group and 12 patients in the control group had surgical evacuation of uterus which was highly significant $(\mathrm{p}=0.000)$.

Table 7: Side effects and satisfaction level after medical abortion.

\begin{tabular}{|llll|}
\hline Vomiting & Group I & Group II & p-value \\
\hline $\begin{array}{l}\text { Abdominal } \\
\text { cramps }\end{array}$ & $21(\mathrm{n}=95)$ & $34(\mathrm{n}=56)$ & 0.000 \\
\hline $\begin{array}{l}\text { Satisfaction } \\
\text { level }\end{array}$ & $33(\mathrm{n}=95)$ & $47(\mathrm{n}=54)$ & 0.640 \\
\hline
\end{tabular}

Abdominal pain and cramping were experienced by 79 women in the control group and 47 women in the study group $(p=0.529)$. the mean duration of abdominal pain in the study group was 3.6 days, whereas in the control group was 1.9 days. nausea and vomiting were reported in 21 patients in the study group and 34 patients in the control group, which was statistically significant $(\mathrm{p}=$ 0.000 ; Table 7). The acceptability as per criteria of 
likelihood of choosing it again and likelihood of recommending it to a friend was $50.84 \%$ in the study group and $81 \%$ in the control group. the difference in level of satisfaction in both the groups was statistically not significant (Table 7). No patient was treated for infection in either group.

\section{DISCUSSION}

Medical abortion is an important alternative to surgical method of abortion and is safe and effective. there is limited data regarding efficacy and safety of medical abortion in hypothyroid patients. this information is important in Indian settings, as there is increased prevalence of clinical and subclinical hypothyroidism in India. According to the study done by nambiar et al hypothyroidism was present in $4.8 \%$ of first-trimester pregnant patients, and $12.8 \%$ of these patients had thyroid autoimmunity. ${ }^{7}$

In a study done in first-trimester preg- nant patients by Dhaniwal et al subclinical hypothyroidism was present in $13.5 \%$ among which $18 \%$ were antithyroperoxidase (tPO) antibody positive individuals. Overt hypothyroidism was seen in $0.7 \%$ pregnant patients, out of which $71.4 \%$ were anti-tPO antibody positive. ${ }^{8}$ Incidence of hypothyroidism in Western countries is reported to be much less at around $2.5 \% .^{9}$ Further during pregnancy, there is increased requirement of thyroid hormones and substantial risk that a previously unnoticed, subclinical, or latent hypothyroidism will turn into overt hypothyroidism. ${ }^{10}$

there is increased presence of anemia in subclinical and overt hypothyroidism. In a study by chanchal Das et al, the presence of anemia in subclinical hypothyroidism and overt hypothyroidism was 26.2 and $78.8 \%$ respectively. ${ }^{11}$ Many other studies have also corroborated the increased prevalence of anemia in hypothyroidism. ${ }^{12,13}$

These findings are consistent with the findings in our study where the average hemoglobin level in the study group was $9.516 \mathrm{gm} \%$ in com- parison with the control group (11.180 gm\%), and the difference was statistically significant. the fall in hemoglobin after 2 weeks of the drug intake was significant in control as well as the study group, with $\mathrm{p}$ value being $<0.001$ and 0.000 respectively.

Although fall in hemoglobin after 2 weeks was significant in both the groups, 8 out of 56 patients $(13.79 \%)$ in the study group complained of excessive bleeding and this subgroup of patients required emergency surgical evacuation to stop bleeding, whereas none of the patients out of 95 in the control group had any such complaints. this difference is highly significant $(\mathrm{p}=0.008)$.

In a large multicenter trial involving 2,000 women who received mife- pristone $200 \mathrm{mg}$ followed by $800 \mu \mathrm{g}$ of misoprostol intravaginally for first-trimester abortion, $0.4 \%$ of patients required surgical aspiration to control bleeding [note: this regimen differs from the food and Drug Administration (fDA)-approved regimen]. ${ }^{14}$ In another multicenter trial in the United States involving 2,121 women, which employed the current fDA-approved regimen (mifepristone $600 \mathrm{mg}$ and $400 \mu \mathrm{g}$ of misoprostol orally till 49 days of last menstrual period), $2.6 \%$ of women required suction curettage to treat excessive bleeding. ${ }^{15}$

There are numerous studies which show that hypothyroidism causes menstrual disturbances. According to Weeks et al, there is association between hypothyroidism and excessive menstrual loss. ${ }^{16}$ In present study, the patients who were hypothyroid also had longer duration of bleeding. the duration of bleeding in the control group was $6.77+2.998$ vs $8.52+3.191$ days in the study group. Although the duration of bleeding in both groups was within normal range of 8 to 15 days, the difference in duration of bleeding between the two groups was statistically significant.

Further studies are needed to substantiate these findings. ${ }^{17}$ It was also seen that in hypothyroid group there was increased frequency of incomplete abortions with $28.5 \%$ of the patients undergoing D\&c after 2 weeks for retained products of conception. this included one case with viable intrauterine pregnancy, which constitutes true failure of the abortifacient drugs. Incomplete abortion was seen in $11.57 \%$ of the patients in the control group, and this difference is statistically significant $(\mathrm{p}=$ 0.000).

Since eight patients in hypothyroid group also had emergency D\&c for excessive bleeding, total of $41 \%$ of the patients in the study group had to ultimately undergo D\&c, which is an extremely high percentage. In contrast in the control group, only $11.57 \%$ patients had D\&c for incomplete abortion and none of the patients had to undergo emergency D\&c. this difference in operative intervention is highly significant $(p=0.000)$. The success rate of medical abortion in the control group is consistent with worldwide data with clinical trials in the United States, Canada, and Turkey reporting complete abortion rate from 85 to $100 \% .^{18}$ In general population, mifepristone and misoprostol combination has a very low incidence of heavy vaginal bleeding so as to require blood transfusion $(<0.2 \%){ }^{14,19,20}$

In present study, 2 patients out of $56(1.12 \%)$ required blood transfusion in the study group, while none of the patients in the control group out of 95 required transfusion.

Although the rate of blood transfusion was slightly higher in the study group in comparison with the above- cited studies, the difference between the study and control groups was not statistically significant. Frequency of minor side effects like nausea and vomiting was also more in the study group in comparison with the control group, which was 22.10 vs $60.714 \%$ respectively. this 
difference between both the groups is statistically significant $(\mathrm{p}=0.00)$.

El-refaey et al reported incidence of vomiting to be about $31 \%$ in their patients after using mifepristone and vaginal misoprostol, whereas frequency of abdominal cramping was 83 vs $87 \%$, which was almost similar in both the groups, overall incidence being $84.56 \% .^{21}$ This is consistent with the study conducted by Spitz et al, who reported incidence of abdominal cramping to be $>96 \% .{ }^{15}$ Level of satisfaction regarding the medical method was comparable in both the groups. No patient in either group was treated for infection. This may be because all patients had received antibiotic prophylaxis.

\section{CONCLUSION}

There is no literature in which patients having clinical or subclinical hypothyroidism have been specifically studied to evaluate the safety of mifepristone and misoprostol combination for medical termination of pregnancy. Present study showed that patients having clinical or subclinical hypothyroidism have more failure rates, more chances of excessive bleeding, and increased duration of bleeding.

Since most of these patients are already having mild anemia, the severity of anemia is likely to increase as was shown in our study. there is significant risk of operative intervention in hypothyroid group.

Hence, we should screen the patients for hypothyroidism even when they do not wish to continue the pregnancy, as the complications are significantly higher when we are doing medical termination of pregnancy. In hypothyroid patients, we need to be more careful and vigilant even for relatively safe procedure of medical abortion.

Funding: No funding sources

Conflict of interest: None declared

Ethical approval: The study was approved by the Institutional Ethics Committee

\section{REFERENCES}

1. Sedgh G, Henshaw SK, Singh S, bankole A, Drescher J. legal abortion worldwide: incidence and recent trends. Int fam Plan Perspect. 2007 Sep;33(3):106-16.

2. Urquhart Dr, Templeton AA, Shinewi F, Chapman M, Hawkins K, McGarry J. The efficacy and tolerance of mifepristone and prostaglandin in termination of pregnancy of less than 63 days gestation: UK Multicentre Study-final results. Contraception. 1997 Jan;55(1):1-5.

3. United Kingdom Multicentre trial. the efficacy and tolerance of mifepristone and prostaglandin in first trimester termination of pregnancy. J Obstet Gynaecol. 1990 Jun;97(6):480-6.

4. Creinin MD. Oral methotrexate and vaginal misoprostol for early abortion. Contraception. 1996 Jul;54(1):15-8.
5. Bachelot A, Cludy 1, Spira A. Conditions for chosing between drug-induced and surgical abortions. Contraception. 1992 Jun;45(6):547-59.

6. Minnisto T, Mendola P, Grewal J. thyroid diseases and adverse pregnancy outcomes in contemporary U.S cohort. J Clin Endocrinol Metab. 2013 Jul;98(7):272533.

7. nambiar V, Jagtap VS, Sarathi V, lila Ar, Kamalanathan S, Bandgar TR et al. Prevalence and impact of thyroid disorders on maternal outcome in Asian-Indian pregnant women. J Thyroid Res. 2011(2011):Article ID 429097.

8. Dhanwal DK, Prasad S, Agarwal AK. High prevalence of subclinical Hypothyroidism during first trimester in north India. Indian J Endocrinol Metab. 2013 Mar;17(2):281-4.

9. lebeau SO, Mandel SJ. thyroid disorders during pregnancy. Endocrinol Metab Clin North Am. 2006 Mar;35(1):117-36.

10. Van den Boogaard E, Vissenberg R, Land JA, Van Wely M, Van der Post JA, Goddijn $M$ et al. Significance of subclinical thyroid dysfunction and thyroid autoimmunity before conception and in early pregnancy: a systematic review. Hum Reprod Update. 2011;17(5):605-19.

11. Das C, Sahana PK, Sengupta N, Giri D, Roy M, Mukhopadhyay P. Etiology of anemia in primary hypothyroid subjects in a tertiary care center in eastern India. Indian J endocrinol Metab. 2012 Dec;16(Suppl 2):S361-S3.

12. Benoist B, Mclean E, Egli I, Cogswell M. Global database on anemia. Geneva: WHO; 2008. Worldwide Prevalence Anemia. 1993-2005:1-2.1.

13. Erdogan M, Kosenli A, Sencer G, Kulaksizoglu M. Characteristics of anemia in subclinical and overt hypothyroid patients. Endocr J. 2012;59(3):213-20.

14. Ashok PW, Penney GC, flett GM, Templeton A. An effective regimen for early medical abortion: a report of 2,000 consecutive cases. Hum Reprod. 1998 Oct;13(10):2962-5.

15. Spitz IM, Bardin CW, Benton 1, Robbins A. early pregnancy termination with mifepristone and misoprostol in the United States. New Engl J Med. 1998 Apr;338:1241-7.

16. Weeks AD. Menorrhagia and hypothyroidism. evidence supports association between hypothyroidism and menorrhagia. BMJ. 2000 Mar;320(7235):649.

17. Royal college of Obstetricians and Gynaecologists. the care of women requesting induced abortion. london: RCOG Press; 2004.

18. Ngo TD, Park MH, Shakur H, Free C. comparative effectiveness, safety and acceptability of medical abortion at home and in clinic: a systematic review. Bull WHO. 2011;89:360-70.

19. Spitz IM, Bardin Bachelot A, Cludy 1, Spira A. conditions for choosing between drug-induced and surgical abortions. Contraception. 1992 Jun;45(6):54759.

20. Winikoff B, Sivin I, Coyaji KJ, Cabezas E, Xiao B, Gu S, Du MK et al. Safety, efficacy, and acceptability of medical abortion in china, cuba, and India: a comparative trial of mifepristone/misoprostol versus 
surgical abortion. Am J Obstet Gynecol. 1997 feb;176(2):431-7.

Cite this article as: Sood N, Sud SS. Effect of the thyroid status in pregnant patients on the outcome in medical abortion. Int $\mathbf{J}$ Reprod Contracept Obstet Templeton A. Induction of abortion with mifepristone (rU 486) and oral or vaginal misoprostol. N Engl J Med. 1995 Apr;332(15):983-7. 